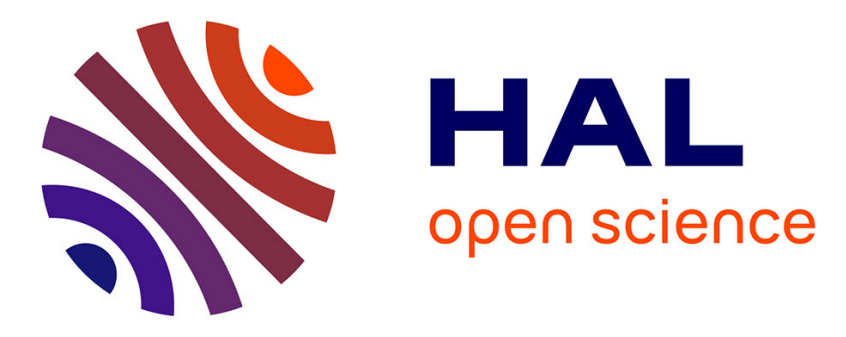

\title{
Synergistic interaction of variants in and on breast cancer risk
}

\author{
Pablo Serrano-Fernández, Tadeusz Dębniak, Bohdan Górski, Natalia \\ Bogdanova, Thilo Dörk, Cezary Cybulski, Tomasz Huzarski, Tomasz Byrski, \\ Jacek Gronwald, Dominika Wokolorczyk, et al.
}

\section{To cite this version:}

Pablo Serrano-Fernández, Tadeusz Dębniak, Bohdan Górski, Natalia Bogdanova, Thilo Dörk, et al.. Synergistic interaction of variants in and on breast cancer risk. Breast Cancer Research and Treatment, 2008, 117 (1), pp.161-165. 10.1007/s10549-008-0249-1 . hal-00535318

\section{HAL Id: hal-00535318 \\ https://hal.science/hal-00535318}

Submitted on 11 Nov 2010

HAL is a multi-disciplinary open access archive for the deposit and dissemination of scientific research documents, whether they are published or not. The documents may come from teaching and research institutions in France or abroad, or from public or private research centers.
L'archive ouverte pluridisciplinaire HAL, est destinée au dépôt et à la diffusion de documents scientifiques de niveau recherche, publiés ou non, émanant des établissements d'enseignement et de recherche français ou étrangers, des laboratoires publics ou privés. 


\title{
Synergistic interaction of variants in $C H E K 2$ and $B R C A 2$ on breast cancer risk
}

\author{
Pablo Serrano-Fernández · Tadeusz Dębniak · Bohdan Górski · Natalia Bogdanova • \\ Thilo Dörk · Cezary Cybulski · Tomasz Huzarski · Tomasz Byrski · \\ Jacek Gronwald · Dominika Wokołorczyk · Steven A. Narod · Jan Lubiński
}

Received: 12 September 2008/Accepted: 5 November 2008/Published online: 22 November 2008

(C) Springer Science+Business Media, LLC. 2008

\begin{abstract}
We studied the effects of BRCA2 and CHEK2 variants on breast cancer risk in two case-control series from Poland and Belarus. The missense BRCA2 variant T1915M was associated with a significant reduction in breast cancer risk $(\mathrm{OR}=0.62 ; 95 \%$ CI $0.49-0.79$; $P=0.0007)$. Modest increases of breast cancer risk were observed for the four analysed CHEK2 variants (I157T, 1100delC, IVS2 $+1 \mathrm{G}>\mathrm{A}$ and del5395) $(\mathrm{OR}=2.2 ; 95 \%$ $1.7-2.8 ; P=0.0001)$. The highest risk was observed among women who carried both a BRCA2 and a CHEK2 variant $(\mathrm{OR}=5.7 ; 95 \%$ CI $1.7-19 ; P=0.006)$. We observed a statistically significant interaction effect
\end{abstract}

P. Serrano-Fernández (凶) · T. Dębniak · B. Górski .

C. Cybulski · T. Huzarski · T. Byrski · J. Gronwald .

D. Wokołorczyk · J. Lubiński

International Hereditary Cancer Center, Department of Genetics and Pathology, Pomeranian Medical University, ul. Połabska 4, 70-115 Szczecin, Poland

e-mail: ihcc@pabloserrano.eu; albifrons@yahoo.com

N. Bogdanova $\cdot$ T. Dörk

Department of Obstetrics and Gynaecology, Hannover Medical

School, Hannover, Germany

N. Bogdanova

Department of Radiation Oncology, Hannover Medical School, Hannover, Germany

N. Bogdanova

NN Alexandrov Research Institute of Oncology and Medical Radiology, Minsk, Belarus

S. A. Narod

Womens College Research Institute, Toronto, ON, Canada between CHEK2 mutations and the BRCA2 substitution $(P=0.03)$. These data suggest that the BRCA2 T1915M polymorphism alone might be associated with a reduced risk of breast cancer, but among CHEK2 mutation carriers, it may lead to an unexpectedly high risk.

Keywords Breast cancer - CHEK2 - BRCA2 Breast cancer - Gene interaction

\section{Introduction}

Major genes for susceptibility to breast cancer include $B R C A 1$ and $B R C A 2$; these genes are characterized by high lifetime penetrance of cancer, with corresponding odds ratios (OR) in excess of ten [1]. Mutations in the CHEK2 gene confer a more modestly elevated risk of breast cancer (OR two to three) [2-4]. The examination of families with mutations suggests that CHEK2 may have an important role in modifying the effects of other cancer susceptibility genes, or vice versa $[5,6]$. For example, we reported that a CHEK2 mutation increases the risk of prostate cancer only among men with a specific genotype of $C D K N 1 B$ (encoding the tumour suppressor $\mathrm{p} 27^{\mathrm{KIP1}}$ ) [7]. The risk of breast cancer in $C H E K 2$ mutation carriers is not significantly modified by the $C D K N 1 B$ genotype, but other genes which are related to cell cycle control or to DNA damage response might interact with $C H E K 2$ in breast carcinogenesis. BRCA2 is such a candidate gene. There are no highly penetrant $B R C A 2$ founder mutations in Poland, but there is a low-penetrance missense variant (C5972T) which predisposes to early-onset breast cancer (age at diagnosis below 40 years $)(\mathrm{OR}=1.4)$ and to ductal cancer in situ (DCIS) with micro-invasion (OR $=2.8)$ [8]. DCIS with micro-invasion is also over-represented among women 
with a CHEK2 mutation. ${ }^{1}$ We have developed a breast cancer registry that contains clinical information, pathology details and DNA specimens from unselected patients with breast cancer for the purpose of identifying the principal genes involved in susceptibility to breast cancer and their interactions. We hypothesized that CHEK2 and $B R C A 2$ mutations might have an interactive effect on breast cancer risk (and possibly be synergistic).

\section{Methods}

Cases

The study was approved by the ethics committee of the Pomeranian University. Cases consisted of 1,022 consecutive women with invasive breast cancer diagnosed in the city of Szczecin, Poland. The patient was invited to participate in person during her hospital stay or through a mailed invitation. During the interview the goals of the study were explained, informed consent was obtained, genetic counseling was given and a blood sample was taken for DNA analysis. A detailed family history of cancer was taken (first, and second-degree relatives included) and a risk factor questionnaire was completed. The medical record and pathology report were reviewed. The median age at diagnosis was 56 years.

A second, independent series of cases was 1,756 women with breast cancer who had been diagnosed during the years 1998-2007 at the Belorussian Institute for Oncology and Medical Radiology Aleksandrov N.N. in Minsk or at one of the regional oncology centers in Gomel, Mogilev, Grodno, Brest or Vitebsk. The series mainly consisted of consecutive patients unselected for family history, with the exception of additional 28 cases with familial breast cancer ascertained at the center in Minsk. Median age at diagnosis in the Belarus cohort was 48 years, and a total of 305 patients $(16 \%)$ reported a first-degree relative with breast cancer.

\section{Controls}

The Polish control subjects consisted of 1,022 healthy women who had no past history of cancer and a negative cancer family history in first- and second-degree relatives. The controls were selected from a database derived from a population-based study of the 1.5 million residents of west Pomerania. During the interview the goals of the study were explained, informed consent was obtained, genetic

\footnotetext{
${ }^{1}$ Cybulski C, Huzarski T, Byrski T, Lubiński J. Estrogen Receptor Status in CHEK2-positive Breast Cancers: Implications for Chemoprevention (submitted for publication).
}

counseling was given and a blood sample was taken for DNA analysis. A detailed family history of cancer was taken (first and second-degree relatives included) and a risk factor questionnaire was completed. Women affected with any malignancy or with one or more cancers diagnosed among first- or second degree relatives were excluded from the controls. For each case, a single control was selected. Cases and controls were matched for sex, year of birth (within 2 years) and geographical origin.

The Belorussian controls were 1,019 female volunteers who had been ascertained during the same time period at the Institute for Inherited Diseases in Minsk, Belarus. Subjects were excluded as controls if they reported a personal history of breast cancer, but further details about family history were not obtained. The controls had the same geographical origin as the patients, but were not matched for year of birth. The median age was 51 years.

\section{Laboratory methods}

We evaluated the presence of four $C H E K 2$ variants in the cases and controls, including one missense variant (I157T) and three truncating variants (1100delC, IVS $2+1 \mathrm{G}>\mathrm{A}$ and del5395). The techniques for detection of these mutations have been described previously $[9,10]$. We evaluated the presence of the common $B R C A 2$ variant $(\mathrm{T} 1915 \mathrm{M})$ in the Polish study using a RFLP PCR technique described previously [8]. Duplicate genotyping for quality control was performed for 92 randomly selected samples for $B R C A 2$ and 462 for $C H E K 2$, but no discrepancies with the initial results were found. As a further check, all mutation-positive cases (positive for the BRCA2 and/or any $C H E K 2$ mutation) were confirmed by sequencing (ABI DNA Sequencer 377, Perkin Elmer), but again with no discrepancies.

In the Belarus study, a $5^{\prime}$-exonuclease allelic discrimination assay was newly established using the primer pair $5^{\prime}$-GGATGATTCAGAGGATATTCTTCATAACTC- $3^{\prime}$ and 5'-GTTGTAAAATTTCTTCACTCTGAATGTCAG- ${ }^{\prime}$, with the allele-specific probes $5^{\prime}$-FAM-AATGTAGCACGCATT CACATAAG-BHQ- $3^{\prime}$ and $5^{\prime}$-YakimaYellow-AATGTAGC ATGCATTCACATAAG-BHQ-3' (variant nucleotide underlined). Primers and probes were obtained from Eurogentec. Allelic discrimination assays were run on an SDS 7000 Sequence Detection System (Applied Biosystems). The call rate was $100 \%$ for both the case and the control series. The presence of a mutation was independently confirmed by direct sequencing using BigDye chemistry and an Avant 3100 Genetic Analyser (Applied Biosystems).

Statistical analysis

The prevalences of each of the five alleles were compared in cases and controls. Both controls and cases were in 
Hardy-Weinberg equilibrium for the CHEK2 variants (when all four variants considered as whole, and when considered one by one) and for the BRCA2 variant, both in the Polish sample and in the Belorussian sample. Odds ratios were generated from two-by-two tables and statistical significance was assessed using the Chi-square Test (with Yates' correction). To evaluate the statistical significance of the observed gene to gene interaction, a multivariate logistic regression was conducted using a model which contained terms for the main effects of the CHEK2 and BRCA2 variants separately, as well as an interaction term for the combined presence of the CHEK2 and $B R C A 2$ variants. For the analysis of the combined data set the model was adjusted for the study group (Poland and Belarus).

\section{Results}

Initially, the main effects of the alleles in the two genes were estimated in the Polish subjects. At least one of the four CHEK2 variants (I157T, 1100delC, IVS2 + 1G > A or de15395) was detected in $11.5 \%$ of the breast cancer cases and in $6 \%$ of the controls (OR $=2.195 \%$ CI 1.5-2.9; $P=0.0001)$. The odds ratio associated with the missense variant I157T was 1.8 (95\% CI 1.3-2.6; $P=0.0015)$ and the odds ratio associated with a truncating mutation was 3.1 (95\% 1.5-6.3; $P=0.0024)$. The T1915M variant of $B R C A 2$ was detected in $5 \%$ of the cases and $6 \%$ of the controls (OR $=0.9 ; 95 \%$ CI 0.6-1.3).

The distribution of CHEK2 and BRCA2 genotypes in the Polish cases and controls are presented in Table 1. There was a modest increase in the risk of breast cancer associated with a $C H E K 2$ mutation alone $(\mathrm{OR}=1.9 ; 95 \% \mathrm{CI}$
1.3-2.6; $P=0.0003)$. Carriers of the $B R C A 2$ allele alone were more abundant among controls, but no protective effect could be demonstrated $(\mathrm{OR}=0.7$; 95\% CI $0.5-1.1$; $P=0.14$ ). However, compared to women who carried neither mutation, women who carried a mutation in both genes were at elevated risk $(\mathrm{OR}=6.8 ; 95 \% \mathrm{CI} 1.5-30$; $P=0.008$ ). To test whether this result reflected a significant synergistic interaction, a logistic regression analysis was performed, which included an interaction term. The results of the logistic model indicate that the effect of the joint genotype was five times greater than expected under a linear model, and the interaction was statistically significant $(P=0.04)$.

We replicated this analysis in a separate set of cases and controls from Belarus (Table 2). At least one of the four CHEK2 variants (I157T, 1100delC, IVS $2+1 \mathrm{G}>\mathrm{A}$ or de15395) was detected in $7 \%$ of the breast cancer cases and in $2.5 \%$ of the controls $(\mathrm{OR}=2.995 \%$ CI 1.9-4.5; $P=0.0001)$. The odds ratio associated with the missense variant I157T was 2.1 (95\% CI 1.3-3.4; $P=0.002)$ and the odds ratio associated with a truncating mutation was 8.5 (95\% 2.6-27; $P=0.0001$ ). The T1915M variant of BRCA2 was detected in $6 \%$ of the cases and $10 \%$ of the controls $(\mathrm{OR}=0.6 ; 95 \%$ CI $0.4-0.8 ; P=0.0005)$.

In the Belorussian set, the presence of the BRCA2 variant on its own appeared to be protective $(\mathrm{OR}=0.6$; $P=0.0003$ ). Again, the combination of $C H E K 2$ and $B R C A 2$ alterations was found to be associated with the highest risk $(\mathrm{OR}=2.9 ; 95 \%$ CI $0.6-13 ; P=0.25)$. A two-gene interaction was plausible $(\mathrm{OR}=1.8)$, but the interaction term was not statistically significant $(P=0.6)$ (Table 2).

Evidence for an interaction remained strong when the cases and controls from the two studies were combined (Table 3). In this combined analysis, the BRCA2 variant on
Table 1 Combined effect of CHEK2 and BRCA2 T1915M variants on breast cancer risk (cases from Poland only)
Table 2 Combined effect of CHEK2 and BRCA2 T1915M variants on breast cancer risk (cases from Belarus only)

\begin{tabular}{lllll}
\hline & $\begin{array}{l}\text { Cases } \\
n=1,022\end{array}$ & $\begin{array}{l}\text { Controls } \\
n=1,022\end{array}$ & OR (95\% CI) & $P$-value \\
\hline Neither mutation & 865 & 904 & Baseline & \\
CHEK2 mutation alone & 104 & 58 & $1.87(1.34-2.62)$ & 0.0003 \\
BRCA2 T1915M alone & 40 & 58 & $0.72(0.48-1.09)$ & 0.14 \\
CHEK2 mutation and T1915M & 13 & 2 & $6.79(1.53-30.2)$ & 0.008 \\
Interaction $C H E K 2 \times$ BRCA2 & & & $5.04(1.04-24.4)$ & 0.04 \\
\hline
\end{tabular}

\begin{tabular}{lclll}
\hline & $\begin{array}{l}\text { Cases } \\
n=1,756\end{array}$ & $\begin{array}{l}\text { Controls } \\
n=1,019\end{array}$ & OR (95\% CI) & $P$-value \\
\hline Neither mutation & 1,534 & 896 & Baseline & \\
CHEK2 mutation alone & 116 & 24 & $2.82(1.81-4.42)$ & 0.0001 \\
BRCA2 T1915M alone & 96 & 97 & $0.56(0.43-0.78)$ & 0.0003 \\
CHEK2 mutation and T1915M & 10 & 2 & $2.92(0.64-13.4)$ & 0.25 \\
Interaction CHEK2 $\times$ BRCA2 & & & $1.79(0.36-8.93)$ & 0.6 \\
\hline
\end{tabular}


Table 3 Combined effect of CHEK2 and BRCA2 T1915M variants on breast cancer risk (cases from Poland and Belarus combined)
Table 4 Combined effect of CHEK2 missense variant (I157T) and BRCA2 T1915M variant on breast cancer risk (cases from Belarus and Poland combined)

\begin{tabular}{lccll}
\hline & $\begin{array}{l}\text { Cases } \\
n=2,778\end{array}$ & $\begin{array}{l}\text { Controls } \\
n=2,041\end{array}$ & OR (95\% CI) & $P$-value \\
\hline Neither mutation & 2,399 & 1,800 & Baseline & \\
CHEK2 mutation alone & 220 & 82 & $2.18(1.68-2.84)$ & 0.0001 \\
BRCA2 T1915M alone & 136 & 155 & $0.62(0.49-0.79)$ & 0.0007 \\
CHEK2 mutation and T1915M & 23 & 4 & $5.71(1.71-19.0)$ & 0.006 \\
Interaction $C H E K 2 \times$ BRCA2 & & & $3.53(1.15-10.85)$ & 0.03 \\
\hline
\end{tabular}

\begin{tabular}{lccll}
\hline & Cases & Controls & OR (95\% CI) & $P$-value \\
& $n=2,778$ & $n=2,041$ & & \\
\hline Neither mutation & 2,472 & 1,813 & Baseline & \\
CHEK2 I157T mutation alone & 153 & 70 & $1.60(1.20-2.14)$ & 0.002 \\
BRCA2 T1915M alone & 136 & 155 & $0.64(0.51-0.82)$ & 0.0004 \\
CHEK2 I157T and BRCA2 T1915M & 17 & 3 & $4.16(1.22-14.2)$ & 0.025 \\
Interaction CHEK2 $\times$ BRCA2 & & & $4.03(1.12-14.5)$ & 0.03 \\
\hline
\end{tabular}

its own appeared protective $(\mathrm{OR}=0.6 ; 95 \%$ CI $0.5-0.8$; $P=0.0007)$, whereas in women with only a CHEK2 mutation, it was associated with an increased risk of breast cancer $(\mathrm{OR}=2.2)$. Compared to women with neither variant, those with both variants were sixfold more prevalent among breast cancer cases $(\mathrm{OR}=5.7$; 95\% CI 1.7-19; $P=0.006)$. The interaction was statistically significant $(P=0.03)$.

We have previously shown that the odds ratios associated with truncating CHEK2 mutations exceed that associated with the missense $C H E K 2$ variant I157T. We repeated the analysis of the combined cases of Poland and Belarus and their corresponding controls, but restricted the analysis to only the common missense CHEK2 variant (Table 4). In combination, the missense variants of the two genes were associated with a fourfold increase in breast cancer risk and, although the sample size of women with both variants was small (17 cases and 3 controls), the interaction was statistically significant $(P=0.03)$.

\section{Discussion}

In Poland, about one in 500 women carries both a $C H E K 2$ mutation and the T1915M missense variant in BRCA2. According to the results from this study, these women may face a risk of breast cancer that is almost seven-fold greater than average. Assuming a background risk of cancer of approximately $5 \%$ to age 70 , we estimate that Polish women with this combination may have a lifetime breast cancer risk of $30-35 \%$. In comparison, about one in 300 Polish women carries a deleterious founder mutation in $B R C A 1$, which is associated with an odds ratio of 15 and a lifetime risk of approximately $70 \%$ [11].
In isolation, neither the CHEK2 I157T nor the BRCA2 T1915M missense variant appear to lead to a strong influence in cancer risk, but when combined, the cancer risk may be increased to a range that becomes clinically important. However, there were relatively few individuals with both variants among our controls and the confidence interval surrounding the odds ratio is wide. It is important that these observations get extended to other populations where these or other founder mutations are present.

To our knowledge, BRCA2 T1915M is at present the only low-penetrance missense variant reported for $B R C A 2$ that seems to be associated with a significant risk modification. As a caveat, our findings warrant confirmation in further replication studies. Another missense substitution, $\mathrm{N} 372 \mathrm{H}$, had initially been proposed as a low-penetrance allele in BRCA2 [12] but was not confirmed in a subsequent large Consortium study [13]. However, it remains possible that other variants in $C H E K 2$ or $B R C A 2$ also participate in an epistatic relationship.

This is the second reported example of a gene-gene interaction involving $C H E K 2$, and it remains to be seen whether it could be of relevance also for other malignancies In 2006, we reported joint effects of $C D K N 1 B$ (encoding the tumour suppressor $\mathrm{p} 27^{\mathrm{KIP} 1}$ ) and $C H E K 2$ variants on prostate and colon cancer risk [7]. Modest effects on prostate cancer risk were observed for $\mathrm{CHEK} 2$ variants (both missense and truncating). The excess cancer risk was restricted to men who were homozygous for the VV genotype in codon 109 of the $C D K N 1 B$ gene. Among men with the VV genotype, the odds ratios associated with truncating and missense CHEK2 mutations were 3.1 $(P<0.0001)$ and $1.9(P<0.0001)$, respectively. Among men with other $C D K N 1 B$ genotypes (GG and VG), the odds ratios were 1.5 and 1.2 for truncating and missense 
CHEK2 mutations, respectively, and were not statistically significant. The interaction between $C H E K 2$ and $C D K N 1 B$ was also present in patients with colon cancer, but not in breast cancer patients.

The evidence for a genetic interaction between $C H E K 2$ and $B R C A 2$ may reflect the functional interaction of their gene products, in DNA damage recognition and repair. For example, a loss of $C H E K 2$ would activate its substrate Cdc25 phosphatase which results in BRCA2 phosphorylation by a cyclin-dependent kinase and subsequent block of homology-directed repair [14]. CHEK2 may also mediate $B R C A 2$ expression at the transcript level via FOXM1 phosphorylation in some cell types [15]. CHEK2 also regulates the function of BRCA1 and the loss of CHEK2mediated BRCAl phosphorylation seems to be accompanied by a switch from the BRCA2-mediated homologydirected repair to the more error prone non homologous end-joining pathway [16]. The BRCA2 T1915M variant is located in exon 11, coding for the domain that interacts with $R A D 51$ and this interaction is necessary for the activation of the BRCA2-mediated homology-directed repair [17].

Our unexpected and surprising observation is that the $B R C A 2$ missense allele appears to protect against breast cancer in most women, but in women who carry a CHEK2 mutation, the cancer risk appears to be augmented. We hypothesize that the BRCA2 T1915M variant alone may be optimal for the efficiency of homology-directed repair, but when combined with a CHEK2 deficiency, this potentially protective effect could be lost due to a failure to switch the appropriate repair pathway. Functional studies will be required to support this speculation.

Our findings raise the possibility that polygenic risk models may be complicated by gene-gene interactions. It has recently been proposed that individual breast cancer risk can be measured by counting the number of deleterious variants present from among panel of seven [18]. This method is practical, but may be simplistic if situations similar to ours with $C H E K 2$ and $B R C A 2$ were more general, rather than exceptional. It appears likely that the CHEK2 gene is an important modifier for the risk of cancer imparted by other genes. It may be possible to identify other genes which interact with CHEK2 in risk modification, and it will be interesting to test additional genes involved in homology-directed repair in this regard.

\section{References}

1. Narod SA, Foulkes WD (2004) BRCA1 and BRCA2: 1994 and beyond. Nat Rev Cancer 4:665-676. doi:10.1038/nrc1431
2. Meijers-Heijboer H, van den Ouweland A, Klijn J et al (2002) Low-penetrance susceptibility to breast cancer due to CHEK2(*)1100delC in noncarriers of BRCA1 or BRCA2 mutations. Nat Genet 31:55-59. doi:10.1038/ng879

3. CHEK2 Breast Cancer Case-Control Consortium (2004) CHEK2*1100delC and susceptibility to breast cancer: a collaborative analysis involving 10,860 breast cancer cases and 9, 065 controls from 10 studies. Am J Hum Genet 74:1175-1182. doi: $10.1086 / 421251$

4. Zhang S, Phelan CM, Zhang P et al (2008) Frequency of the CHEK2 1100delC mutation among women with breast cancer: an international study. Cancer Res 68:2154-2157. doi:10.1158/ 0008-5472.CAN-07-5187

5. Johnson N, Fletcher O, Naceur-Lombardelli C, dos Santos Silva I, Ashworth A, Peto J (2005) Interaction between CHEK2* $1100 \mathrm{delC}$ and other low-penetrance breast-cancer susceptibility genes: a familial study. Lancet 366:1554-1557. doi:10.1016/ S0140-6736(05)67627-1

6. Oldenburg RA, Kroeze-Jansema K, Kraan J et al (2003) The CHEK2*1100delC variant acts as a breast cancer risk modifier in non-BRCA1/BRCA2 multiple-case families. Cancer Res 63:8153-8157

7. Cybulski C, Gliniewicz B, Sikorski A et al (2007) Epistatic relationship between the cancer susceptibility genes CHEK2 and p27. Cancer Epidemiol Biomarkers Prev 16:572-576. doi: 10.1158/1055-9965.EPI-06-0566

8. Górski B, Narod SA, Lubiński J (2005) A common missense variant in BRCA2 predisposes to early onset breast cancer. Breast Cancer Res 7:R1023-R1027. doi:10.1186/bcr1338

9. Cybulski C, Wokołorczyk D, Huzarski T et al (2007) A deletion in CHEK2 of 5, 395 bp predisposes to breast cancer in Poland. Breast Cancer Res Treat 102:119-122. doi:10.1007/s10549006-9320-y

10. Cybulski C, Górski B, Huzarski T et al (2004) CHEK2 is a multiorgan cancer susceptibility gene. Am J Hum Genet 75: 1131-1135. doi:10.1086/426403

11. Górski B, Cybulski C, Huzarski T et al (2005) Breast cancer predisposing alleles in Poland. Breast Cancer Res Treat 92: 19-24. doi:10.1007/s10549-005-1409-1

12. Healey CS, Dunning AM, Teare MD et al (2000) A common variant in BRCA2 is associated with both breast cancer risk and prenatal viability. Nat Genet 26:362-364. doi:10.1038/81691

13. Breast Cancer Association Consortium (2006) Commonly studied single-nucleotide polymorphisms and breast cancer: results from the Breast Cancer Association Consortium. J Natl Cancer Inst 98:1382-1396

14. Esashi F, Christ N, Gannon J et al (2005) CDK-dependent phosphorylation of BRCA2 as a regulatory mechanism for recombinational repair. Nature 434:598-604. doi:10.1038/ nature 03404

15. Tan Y, Raychaudhuri P, Costa RH (2007) CHK2 mediates stabilization of the FOXM1 transcription factor to stimulate expression of DNA repair genes. Mol Cell Biol 27:1007-1016. doi:10.1128/MCB.01068-06

16. Zhang J, Willers H, Feng Z et al (2004) CHK2 phosphorylation of BRCA1 regulates DNA double-strand break repair. Mol Cell Biol 24:708-718. doi:10.1128/MCB.24.2.708-718.2004

17. Thorslund T, Esashi F, West SC (2007) Interactions between human BRCA2 protein and the meiosis-specific recombinase DMC1. EMBO J 26:2915-2922. doi:10.1038/sj.emboj.7601739

18. Pharoah PD, Antoniou AC, Easton DF, Ponder BA (2008) Polygenes, risk prediction, and targeted prevention of breast cancer. N Engl J Med 358:2796-2803. doi:10.1056/NEJMsa0708739 